\title{
Biología alimentaria de Prochilodus mariae durante la primera fase de crecimiento
}

\author{
The Prochilodus mariae feeding habits during \\ their first growth phase
}

\section{Biología alimentar de Prochilodus mariae durante a primeira fase de crescimento}

\author{
Elizabeth Aya-Baquero ${ }^{1}$ Bióloga, MSc; José A Arias-Castellanos ${ }^{1}$ Biólogo, MSc, PhD; \\ Sandra Milena Hernández-Herrera ${ }^{1}$ Bióloga
}

\footnotetext{
1 Programa de Biología, Facultad de Ciencias Básicas e Ingeniería, Universidad de los Llanos, Villavicencio, Meta, Colombia Email: elizabeth.aya@unillanos.edu.co
}

Recibido: 08 de agosto de 2018

Aceptado: 07 de septiembre de 2020

\begin{abstract}
Resumen
Entre los más importantes peces del río Meta se encuentra Prochilodus mariae (bocachico llanero o coporo), tanto por su mayor tamaño dentro de los bocachicos de la cuenca, como por su aporte a la biomasa trófica y de las pesquerías de la región. En el presente trabajo se evaluó el régimen alimenticio de poslarvas (inicio de la alimentación exógena) del coporo Prochilodus mariae, hasta el inicio de la fase de alevino (aletas completas y cuerpo con escamas), en condiciones simuladas durante los primeros 30 días de alimentación exógena. Los estanques en tierra del IALL, asignados para el desarrollo de este trabajo, fueron abonados orgánicamente con (bovinaza y heno) teniendo en cuenta las condiciones que suceden cada año, a las entradas de aguas en las áreas de inundación de los afluentes, los que fueron sembrados con larvas obtenidas por reproducción inducida a densidad de veinte larvas $/ \mathrm{m}^{2}$ y con el $80 \%$ de su saco vitelino absorbido. Cada dos días, durante 30 días, a las 8:00 h, fueron colectadas poslarvas junto con las muestras de zooplantcton y fitoplancton y fijados en formol bufferado al $4 \%$. Los índices de frecuencia (IF) de los contenidos estomacales de siete poslarvas/estanque y los ítems alimenticios como oferta hallados en aguas y perifiton fueron evaluados. Los análisis se realizaron con un total de 156 ejemplares que oscilan entre intervalos de 6-8.99; 9-17.99; 18-26.99; 27-35.99; 36-44.99; 45-47.99 mm de longitud total. Las poslarvas del primer intervalo exploran organismos relacionados con el perifiton principalmente bacterias, protozoos y algas en este primer muestreo se caracterizó porque el $66.7 \%$ de las poslarvas presentaron estómagos vacíos. En las poslarvas del segundo intervalo el IF de los contenidos mostró una tendencia por el consumo de organismos pelágicos con preferencia por los cladóceros. En el último intervalo los alevinos inician el consumo de detritos (materia orgánica particulada, bacterias, hongos) y otras formas del fitoplancton cercano a las paredes y fondo del estanque.
\end{abstract}

Palabras clave: Bocachico, coporo, detritívoro, larvicultura, nivel trófico, primera alimentación. 


\begin{abstract}
Prochilodus mariae (bocachico llanero or coporo) is amongst the most important fish in the Meta River (a major left tributary of the Orinoco River); along with being the largest of the Prochilodus species in the river basin, flannel-mouth characiforms contribute greatly to the dynamics of the region's food chain and fisheries. This work was aimed at assessing Prochilodus mariae post-larvae feeding habits during their first thirty days of exogenous feeding until the beginning of the alevin stage. Simulations were made in the Instituto de Acuicultura de los Llanos (IALL) facilities' earthen fish ponds to closely resemble the fishes' natural annual water and feeding conditions. The ponds had been organically fertilised with cattle manure and hay and were then periodically inundated and drained to simulate the Meta River's tributaries natural/annual floodplains or areas that are periodically inundated by high water levels. The ponds were stocked with larvae obtained by artificial spawning at twenty larvae $/ \mathrm{m}^{2}$ density when around $80 \%$ of their yolk sacs had been absorbed. Post-larvae and pond water samples containing zooplankton and phytoplankton were collected at 8 am every other day for 30 days and fixed in $4 \%$ buffered formalin. Seven post-larvae/pond stomach/gut contents (frequency of fullness index - FI) were analysed from 156 specimens divided into size intervals ranging from 6-8.99, 9-17.99, 18-26.99, 27-35.99, 36-44.99 and 45-47.99 mm in length. Food items' frequency of abundance (i.e. supply) in the pond water and periphyton were estimated. First-size interval post-larvae explore periphyton-related organisms for their food source (mainly bacteria, protozoans and algae). This first sampling was characterised by $66.7 \%$ of the post-larvae having empty stomachs. Second-size interval post-larvae FI tended reflect the consumption of pelagic organisms, having a preference for microcrustaceans (cladocerans and copepods). The longest alevins (45-47.99 mm long) started consuming detritus (particulate organic matter, bacteria and fungi) and other forms of phytoplankton close to the sides and bottom of the fishponds.
\end{abstract}

Keywords: Prochilodus, bocachico, detritivore, larviculture, trophic level, first feeding.

\begin{abstract}
Resumo
Entre os peixes mais importantes do rio Meta encontra-se Prochilodus mariae (bocachico llanero ou coporo), devido a ser dos maiores bocachicos da bacia, assim como a sua contribuição para a biomassa trófica e pesca da região. O presente trabalho pretende avaliar a dieta das pós-larvas do coporo Prochilodus mariae, até ao início da fase de alevinos em condições simuladas durante os primeiros trinta dias de alimentação exógena. Os estanques do IALL destinados ao desenvolvimento deste trabalho, foram fertilizados organicamente com (esterco bovino e feno) atendendo às condições que ocorrem a cada ano, na entrada de água nas áreas de alagamento dos afluentes, que foram semeados com larvas obtidas por reprodução induzida na densidade de vinte larvas / $\mathrm{m} 2$ e com $80 \%$ do saco vitelino absorvido. A cada dois dias, durante 30 dias, às 8:00 da manhã, as pós-larvas eram recolhidas juntamente com a água, e fixadas em formalina tamponada a 4\%. Foram avaliados os índices de frequência (IF) do conteúdo estomacal de sete pós-larvas/tanque e itens alimentares encontrados nas águas e perifiton. As análises foram realizadas com um total de 156 espécimes entre 6-8,99; 9-17,99; 18-26,99; 27-35:99; 36-44,99; 45-47,99mm de comprimento total. As pós-larvas do primeiro intervalo exploram organismos relacionados com o perifiton principalmente bactérias, protozoários e algas, esta primeira amostragem foi caracterizada porque $66,7 \%$ das pós-larvas apresentavam estômagos vazios. Nas pós-larvas do segundo intervalo o IF do conteúdo estomacal mostrou uma tendência para o consumo de organismos pelágicos com preferência pelos cladóceros. No último intervalo, os alevinos começam a consumir detritos (partículas orgânicas, bactérias, fungos) e formas de fitoplâncton ligadas às superfícies do substrato (feno) e ao fundo do tanque.
\end{abstract}

Palavras-chave: Bocachico, coporo, detritívoro, larvicultura, nível trófico, primeira alimentação.

\section{Introducción}

Prochilodus mariae (bocachico llanero o coporo), es una especie de la cuenca del Orinoco, tiene gran importancia tanto ecológica como comercial en ecosistemas acuáticos, siendo la segunda especie de mayor importancia con un aporte de 153.4 toneladas/año (MADR y CCl, 2010). Se han realizado estudios en pesquerías, manejo de primera alimentación en cultivo, pero aún existen vacíos de información en el conocimiento por la preferencia del nivel trófico durante los primeros días de vida. AriasGallo et al., (2010) determinaron que es común en larvas pelágicas, al iniciar la alimentación exógena posean, una mandíbula funcional y un desarrollo del tracto digestivo, que le permita a la larva reac- cionar al estímulo lumínico, detectar presas perifíticas, zooplanctónicas y predadores potenciales en la columna de agua y comenzar a alimentarse cuando las reservas del saco vitelino sean absorbidas. López et al., (2005), determinaron que estructuras como la boca y el intestino se desarrollan durante la vida larval, aun antes de reabsorber por completo el saco vitelino, situación que permite el inicio de la alimentación exógena. Sánchez et al., (2003), la definen como especie detritívora o sedibentófaga, con boca protráctil y labios gruesos que le ayudan a succionar sedimentos, además posee branquiespinas papilosas, estómago reducido especializado con molleja de pared muscularizada. Esto último les permite triturar mediante granos de arena, el material orgánico, además presenta un intestino muy 
largo y numerosos ciegos pilóricos que incrementan el área de absorción. Estas características les permiten optimizar la deglución y absorción de materiales detríticos y elementos orgánicos poco particulados. Atencio-García et al., (2003), realizaron un estudio en Prochilodus magdalenae cuyos resultados sugieren que nauplios de artemia o zooplancton son presas adecuadas para el manejo de la primera alimentación. Beltrán et al., (2001). Consideran que el coporo es una especie importante ecológicamente porque se ubica en la base de la red trófica ya que es detritívora, cumpliendo un rol fundamental en el ciclo de nutrientes, debido a que toma la materia orgánica y los minerales de los sedimentos y los hace disponibles a las otras especies ícticas.

Donoso et al., (1997), en trabajo realizado con $P$. magdalenae, concluyeron que a medida que aumenta el tamaño de la pos larva de bocachico, disminuye el tamaño de la partícula ingerida, tendiendo una preferencia por partículas finas, que más adelante le determinaran la condición de consumidor de detrito.

Bustamante et al., (1997), recomiendan proporcionar alimento vivo a las larvas a partir del momento que inician nado horizontal, para evitar mortalidades al momento de la siembra en los estanques en tierra. P. mariae, en la primera semana consumen rotíferos, luego muestran preferencia por los cladóceros, cuando no tienen una fuente de zooplancton suplen sus necesidades con algas de diversos tipos.

El factor limitante para el desarrollo de su piscicultura se ha presentado en la producción de alevinos, debido a la alta tasa de mortalidad en la primera fase de crecimiento, problema que se deriva de la falta de conocimiento sobre la alimentación de las larvas y las poslarvas en condiciones naturales que puedan dar los soportes científicos y técnicos para la cría de estas en confinamiento (Arias, 1995). En este estudio, se aportan bases que permiten avanzar en el desarrollo de la piscicultura de $P$. mariae, evaluando las preferencias alimenticias en etapas iniciales.

\section{Materiales y métodos}

\section{Ubicación del experimento}

Los experimentos se desarrollaron en la Estación Piscícola del Instituto de Acuicultura de los Llanos, en tanto que los estudios de los organismos en el Laboratorio de Biología de la Facultad de Ciencias Básicas e Ingeniería, de la Universidad de los Llanos en Villavicencio, Meta, Colombia.

\section{Material biológico}

Larvas obtenidas mediante reproducción inducida fueron sembradas a las 72 horas pos-eclosión (HPE), cuando presentaban apertura oral y anal, natación horizontal y un remanente del $20 \%$ del saco vitelino, en dos estanques de tierra de $250 \mathrm{~m}^{2}$ preparados previamente simulando condiciones naturales como sigue; los estanques secos durante tres semanas fueron abonados uniformemente con bovinaza seca a razón de $10 \mathrm{~g} / \mathrm{m}^{2}$ y $2 \mathrm{~g} / \mathrm{m}^{2}$ de heno comercial Pennisetum clandestinum, y luego llenados lentamente durante 7 días al cabo de los cuales se sembraron 20 larvas $/ \mathrm{m}^{2}$.

Desde el día de la siembra, cada dos días hasta por 30 días, a las 8:00 h, fueron muestreadas las aguas y los organismos. Los parámetros de calidad de agua; (temperatura, $\mathrm{pH}$, registrados con el $\mathrm{pHmetro}$ portátil Hanna instruments ( $\mathrm{pH} / \mathrm{ORP} / \mathrm{Temp})$. Oxígeno disuelto, con el oxímetro portátil HI98196 Hanna instruments. Conductividad con un conductímetro portátil $(0,0 \mu \mathrm{S})$ $\mathrm{cm})$ Hanna. Dureza, (Test kit dureza total Hanna, rango 0,0-53 mg $\mathrm{CaCO}_{3}$ ). Alcalinidad y acidez HI3813. Fueron registrados según Boyd (1996). Para el muestreo de plancton y fitoplancton se aplicó la metodología de Gaviño, et al., (1982) citado por Sánchez et al., 2013, fue colectado con red de $60 \mu \mathrm{m}$ de ojo de malla, hasta completar $10 \mathrm{~L}$, luego este fue concentrado en un tamiz de $15 \mu \mathrm{m}$ hasta un volumen de 10 $\mathrm{mL}$ y fijado, inmediatamente, con formol bufferado al 4\%. Para evaluar el perifiton se aplicó la metodología propuesta por Roldán (2008), se tomó una superficie foliar de $16 \pm 1 \mathrm{~cm}^{2}$, de heno colectado en cada caso, fueron lavados cuidadosamente y desprendidos los organismos y concentrados en $10 \mathrm{~mL}$ y fijados con 0.4 $\mathrm{ml}$ de formol bufferado del $4 \%$ más $0.4 \mathrm{ml}$ de solución de lugol. Nueve poslarvas/estanque/muestreo, fueron colectados y fijados en formol bufferado al $4 \%$. Los organismos de cada muestreo descrito fueron contados con la ayuda de una cámara de microfotografía NIKON Digital, SIGHT DS-U1, Japón, acoplada a un microscopio de contraste de fase (NIKON, Japón). Para la identificación y determinación de los microorganismos se siguió a Heinz y Dieter (1987). La abundancia del perifiton se determinó teniendo en cuenta el número de individuos/área. Para la abundancia del plancton pelágico se tomaron tres sub-muestras de $0.05 \mathrm{ml}$ del concentrado, las que fueron colocadas en cámara de Neubauer y luego observadas al microscopio óptico para registrar un inventario de todos los organismos presentes. Para las muestras de bentos se analizaron aplicando la metodología descrita por Roldán (2008). En poslarvas con tubo digestivo no diferenciado se analizó el contenido total y en los individuos más desarrollados se estudió solo el contenido estomacal. Para 
el análisis de los contenidos intestinales y estomacales se retiró el tubo digestivo de cada individuo y luego se raspó y se colocó el contenido en una cámara de Neubauer a la que se le agregó 0.05 mL de agua destilada. Las observaciones bajo el microscopio siguieron los procedimientos descritos por (Hyslop, 1980; Rossi, 1992; Atencio et al., 2003).

Los registros fueron agrupados por tallas de individuos, por fechas y por desarrollo aparente del tubo digestivo $\mathrm{v} / \mathrm{s}$ ítems alimenticios, y con ello se elaboraron tablas de análisis con índice de frecuencia (IF) de los contenidos y la oferta de los microorganismos en el estanque por origen (perifiton, plancton, bentos), en porcentaje de la oferta.

El Índice de Frecuencia de los contenidos estomacales se calculó, según Mar-Silva et al., (2014), aplicando la fórmula: IF = n/Ne

Donde:

$\begin{array}{ll}n= & \begin{array}{l}\text { Representa el número de estómagos que contiene } \\ \text { dicho alimento }\end{array} \\ N e= & \text { Número de estómagos analizados }\end{array}$

Si f es menor de 0.10 el alimento es accidental

Si f es mayor a 0.10 y menor a 0.5 el alimento es secundario

Si f es mayor a 0.5 el alimento es preferencial

\section{Resultados}

En la Tabla 1, se observan los parámetros físico-químicos evaluados en los estanques durante el período de muestreo. Los resultados presentaron muy pocas variaciones, $\mathrm{T}^{\circ}: 26.5 \pm 0.5, \mathrm{pH}: 6.3 \pm 0.5$, OD: $6.2 \pm 0.3 \mathrm{mg} / \mathrm{l}$, alcalinidad: $11.5 \pm 3 \mathrm{mg} / \mathrm{l}$, dureza: $16 \pm 8 \mathrm{mg} / \mathrm{I} \mathrm{CaCO}_{3}$ y Conductividad: $15 \pm 4 \mu \mathrm{S} / \mathrm{cm}$.

Como se puede apreciar en la Tabla 2, las poslarvas con intervalo de 6 - $8.99 \mathrm{~mm}$, de longitud total (LT) mostraron una tendencia por el perifiton, en los contenidos estomacales (CE), presentaron un $15.9 \%$ de algas clorofíceas. Un $66.7 \%$ de las poslarvas muestreadas presentaron estómagos vacíos. En la Tabla 3, los contenidos estomacales de las poslarvas con intervalos 9-11.99; 12-14.99 mm de LT, presentan en los CE, microcrustáceos (cladóceros y copépodos) en porcentajes de 50.7 y $72.0 \%$ ofertados, en su gran mayoría, por el plancton pelágico. El bentos aporta un porcentaje secundario como alimento pero en los CE, no se observó presencia de este.
En los intervalos de 15-17.99; 18-20.99; 21-23.99 mm de LT (Tabla 4), se observó un incremento en el consumo de alimento de tipo secundario por algas Zignemophyceae, ofertadas por el bentos. Las poslarvas presentaron una tendencia a consumir detritos incrementándose a medida que aumenta la longitud total de las mismas.

En las tablas 5 y 6 , se observan las poslarvas con intervalos de 24-26.99; 27-29.99, 30-32.99; 33-35.99; 36-38.99 y 39-41.99 mm de LT, las cuales mostraron un mayor consumo de algas Zignemophyceae y de detritos ofertados en su mayor parte por el bentos.

Los alevinos con intervalo de 42-44.99 y 45-47.99 mm de LT, presentaron un consumo de algas Bacillariophyceae de tipo accidental (10 y $18 \%$ ) y preferencia por los detritos. Los dos ítems fueron ofertados por el bentos (Tabla 6), el cual representó el 83,7\% de la ingesta alimenticia.

\section{Discusión}

En el presente trabajo se estudiaron las preferencias alimenticias por las poslarvas y el inicio de alevinaje de $P$. mariae, en estanques en tierra que fueron abonados orgánicamente con bovinaza y heno, condiciones simuladas a las presentadas en zonas de rebalse y/o llanuras de inundación, permitiendo el desarrollo de comunidades perifíticas, planctónicas y de bentos. Según Donato (1987), reporta que en el ambiente natural, luego de la época de sequía, se inicia la época anegada, donde las comunidades de perifiton cambian en su composición y estructura. Las especies dominantes del perifiton están rodeadas de copiosas envolturas de mucílago, como se pudo observar en Microcystis, Sphaerocystis, Eremosphaera, encontradas en este trabajo.

En este estudio, las poslarvas con intervalo de 6-8.99 mm de LT, comenzaron su alimentación exógena. Rossi (1992) observó que Prochilodus lineatus inició alimentación exógena a partir de $7.5 \mathrm{mmm}$ de longitud total. Un $66.67 \%$ presentaron estómagos vacíos (Tabla $3)$, probablemente porque conservaban un remanente de saco vitelino. Las poslarvas consumen perifiton debido a la poca agilidad y experticia para capturar el plancton pelágico (López et al., 2005). Los detritos ofertados por el bentos representan el $20.7 \%$ pero en los contenidos estomacales todavía no hay presencia de ellos, debido a que presentan un tubo digestivo muy incipiente, sin un verdadero estómago muscular (molleja) que le ayude a triturar estos detritos (Sánchez et al., 2003). 
Tabla 1. Parámetros físico-químicos del agua en los dos estanques. $\mathrm{T}^{\circ}$, temperatura OD, oxígeno disuelto.

\begin{tabular}{|c|c|c|c|c|c|c|c|}
\hline Fecha & Est. & $\mathbf{T}^{\circ}\left({ }^{\circ} \mathbf{C}\right)$ & $\mathrm{pH}$ & $\mathrm{OD}(\mathrm{mg} / \mathrm{L})$ & $\begin{array}{c}\text { Alcalinidad } \\
(\mathrm{mg} / \mathrm{L}) \mathrm{CaCO} 3\end{array}$ & $\begin{array}{l}\text { Dureza Total } \\
(\mathrm{mg} / \mathrm{L}) \mathrm{CaCO} 3\end{array}$ & $\begin{array}{c}\text { Conductividad } \\
\mu \mathrm{S} / \mathrm{cm}\end{array}$ \\
\hline $15 / 04 / 2014$ & $\mathrm{C} 7$ & 26,4 & 5,3 & 6,0 & 10 & 20 & 20 \\
\hline $16 / 04 / 2014$ & $\mathrm{C} 7$ & 26,7 & 6,0 & 6,3 & 10 & 10 & 20 \\
\hline $17 / 04 / 2014$ & $\mathrm{C} 7$ & 27,6 & 6,0 & 6,0 & 10 & 40 & 20 \\
\hline $19 / 04 / 2014$ & $\mathrm{C} 7$ & 27,0 & 6,4 & 6,2 & 10 & 15 & 15 \\
\hline $21 / 04 / 2014$ & $\mathrm{C7}$ & 27,6 & 6,0 & 6,0 & 11 & 20 & 10 \\
\hline $23 / 04 / 2014$ & $\mathrm{C} 7$ & 26,0 & 6,6 & 6,8 & 15 & 10 & 10 \\
\hline $25 / 04 / 2014$ & $\mathrm{C} 7$ & 26,6 & 6,4 & 6,4 & 10 & 20 & 10 \\
\hline $27 / 04 / 2014$ & $\mathrm{C} 7$ & 27,0 & 6,8 & 6,0 & 20 & 10 & 10 \\
\hline $29 / 04 / 2014$ & $\mathrm{C} 7$ & 27,6 & 6,0 & 6,0 & 11 & 15 & 10 \\
\hline $01 / 05 / 2014$ & $\mathrm{C} 7$ & 27,6 & 6,0 & 6,0 & 10 & 20 & 20 \\
\hline 03/05/2014 & $\mathrm{C} 7$ & 26,6 & 7,1 & 6,4 & 15 & 10 & 20 \\
\hline $07 / 05 / 2014$ & $\mathrm{C} 7$ & 26,8 & 6,5 & 5,9 & 10 & 14 & 20 \\
\hline $10 / 05 / 2014$ & $\mathrm{C} 7$ & 26,0 & 6,0 & 6,0 & 10 & 10 & 10 \\
\hline $16 / 05 / 2014$ & $\mathrm{C} 7$ & 26,7 & 7,2 & 6,7 & 10 & 10 & 15 \\
\hline $15 / 04 / 2014$ & $\mathrm{C} 8$ & 26,0 & 5,5 & 6,0 & 10 & 40 & 10 \\
\hline $16 / 04 / 2014$ & $\mathrm{C} 8$ & 29,0 & 6,0 & 6,4 & 10 & 20 & 20 \\
\hline $17 / 04 / 2014$ & C8 & 26,0 & 6,0 & 6,4 & 10 & 30 & 20 \\
\hline $19 / 04 / 2014$ & $\mathrm{C} 8$ & 27,2 & 6,5 & 6,6 & 15 & 20 & 15 \\
\hline $21 / 04 / 2014$ & $\mathrm{C} 8$ & 28,0 & 6,9 & 6,5 & 11 & 20 & 20 \\
\hline $23 / 04 / 2014$ & $\mathrm{C} 8$ & 25,2 & 6,2 & 6,7 & 13 & 10 & 10 \\
\hline $25 / 04 / 2014$ & $\mathrm{C} 8$ & 26,4 & 6,4 & 6,4 & 10 & 10 & 10 \\
\hline $27 / 04 / 2014$ & C8 & 26,7 & 6,5 & 6,4 & 10 & 10 & 10 \\
\hline $29 / 04 / 2014$ & $\mathrm{C} 8$ & 28,0 & 6,7 & 6,4 & 11 & 12 & 20 \\
\hline $01 / 05 / 2014$ & $\mathrm{C} 8$ & 26,2 & 6,3 & 5,8 & 10 & 10 & 15 \\
\hline 03/05/2014 & $\mathrm{C} 8$ & 26,3 & 6,6 & 6,0 & 15 & 12 & 15 \\
\hline $07 / 05 / 2014$ & $\mathrm{C} 8$ & 27,0 & 6,9 & 5,5 & 14 & 12 & 15 \\
\hline $10 / 05 / 2014$ & $\mathrm{C} 8$ & 26,0 & 6,7 & 6,4 & 10 & 10 & 17 \\
\hline $16 / 05 / 2014$ & $\mathrm{C} 8$ & 26,0 & 6,8 & 6,2 & 10 & 10 & 17 \\
\hline Promedio & & 26,8 & 6,4 & 6,2 & 11,5 & 16,1 & 15,1 \\
\hline Desvest & & 0,8 & 0,5 & 0,3 & 2,5 & 8,5 & 4,3 \\
\hline
\end{tabular}

Las poslarvas de 9-11.99; 12-14.99; 15-17.99 mm de LT, son muy activas y nadan libremente, presentaron preferencia por el consumo de microcrustáceos, preferiblemente cladóceros y copépodos; Rossi (1992), afirma que los cladóceros, constituyen una parte importante de la biomasa de comunidades en el planc- ton. Se destacan por su transferencia de materia y energía desde los microproductores primarios y las fuentes de detritos y bacterias hacia los niveles de los consumidores superiores. Rossi (1992) y Paggi (2005), destacan que los cladóceros son alimento importante en poslarvas de especies que en estado ocupen otros 


\begin{tabular}{|c|c|c|c|c|c|c|c|c|c|c|c|c|c|}
\hline & $\infty$ & $\stackrel{\nabla}{0}$ & o. & $\stackrel{\llcorner}{\longrightarrow}$ & $\stackrel{2}{\sigma}$ & & & $=$ & $\begin{array}{l}\ddagger \\
0\end{array}$ &  & $\frac{1}{6}$ & ְ̧ & \\
\hline$\dot{8}$ & 2 & $\stackrel{+}{+}$ & $\overbrace{}^{2}$ & $\begin{array}{l}\infty \\
0 \\
0\end{array}$ & $\stackrel{m}{=}$ & $0^{n}$ & $\begin{array}{l}\stackrel{\llcorner}{-} \\
\stackrel{m}{-}\end{array}$ & $\bar{s}$ & $\tilde{o}^{n}$ & $\overline{0}$ & $\begin{array}{l}\text { वे } \\
\text { ते }\end{array}$ & $\stackrel{n}{\sim}$ & \\
\hline$\stackrel{\circ}{\circ}$ & $a$ & $\stackrel{1}{0}$ & $=$ & $\cong$ & $\stackrel{े}{\mathrm{i}}$ & & $\hat{o}$ & $\tilde{o}$ & $\bar{i}$ & 5 & $\sigma^{2}$ & $\stackrel{\circ}{-}$ & \\
\hline & $\stackrel{\imath}{u}$ & $\stackrel{\sim}{i}$ & $\hat{\kappa}$ & $\begin{array}{c}0 \\
\infty\end{array}$ & $\begin{array}{l}0 \\
\stackrel{0}{0} \\
\sim\end{array}$ & $\sigma$ & $\bar{i}$ & $\begin{array}{l}\sigma \\
\sigma\end{array}$ & $\begin{array}{l}\sim \\
\sim\end{array} \mid$ & $\begin{array}{l}0 \\
0 \\
\dot{q} \\
+\end{array}$ & ผै & & $\stackrel{\curvearrowright}{\sim}$ \\
\hline & & & $0^{\circ}$ & $\stackrel{\infty}{-}$ & & & & & $\begin{array}{l}10 \\
0\end{array}$ & $\begin{array}{l}3 \\
\tilde{n}^{0}\end{array}$ & $\stackrel{5}{\rightarrow}$ & $\begin{array}{l}\Omega \\
=\end{array}$ & \\
\hline
\end{tabular}

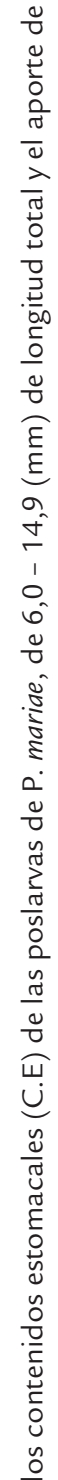



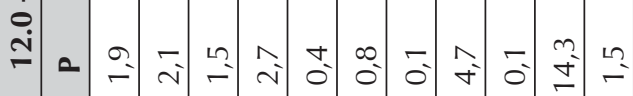

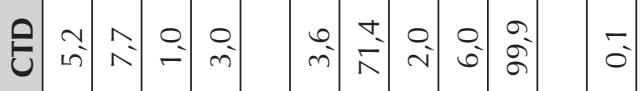

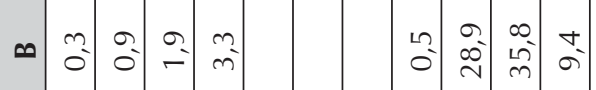

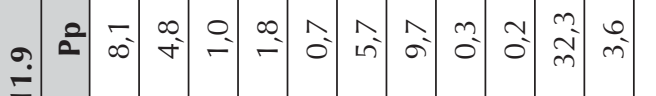

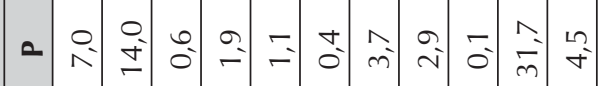

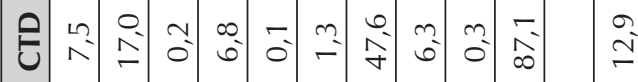

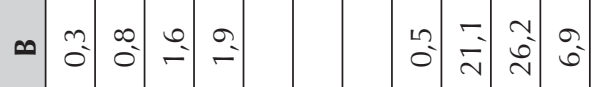

Lூر



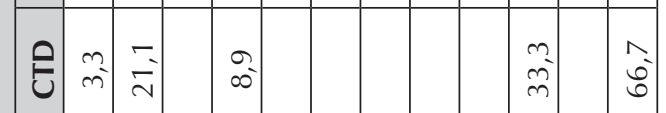

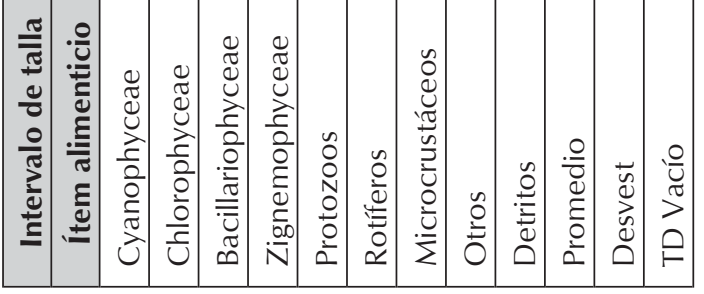

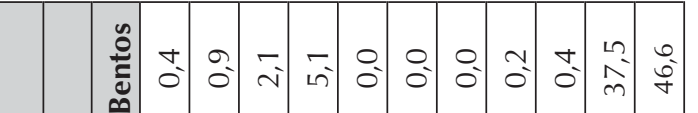

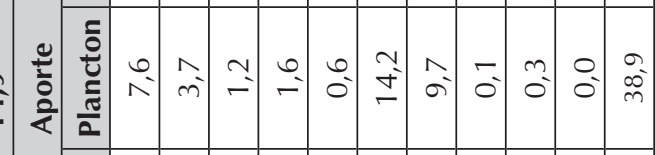

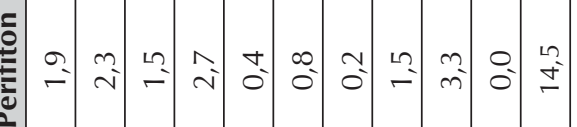

U

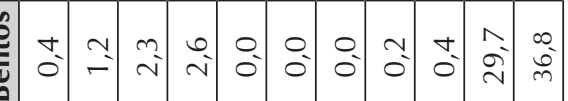

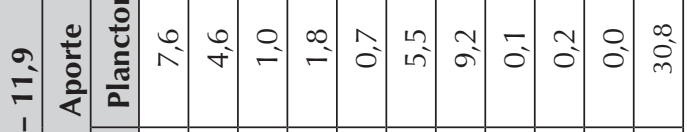

के

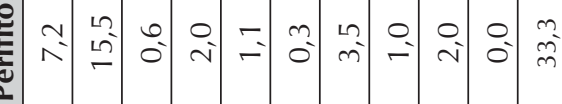

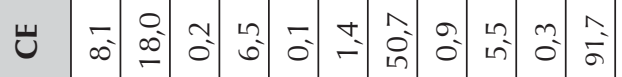

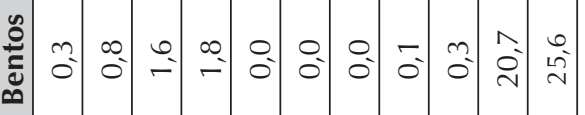

은

$\infty$

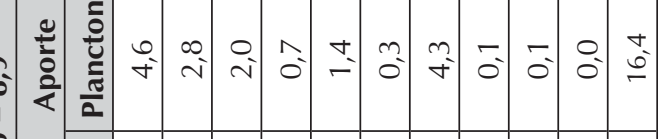

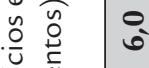

ธ

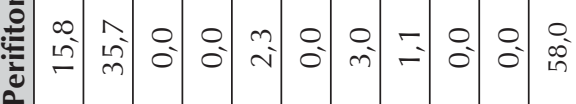

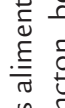

है

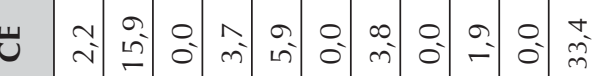

离高



$\frac{\pi}{\tilde{c}} \frac{\tilde{u}}{2}$

恶 $\frac{2}{\mathrm{C}}$

艺

mi

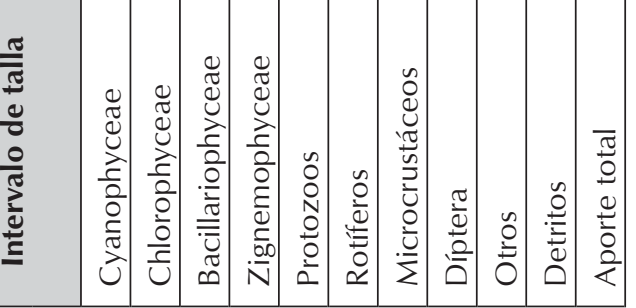




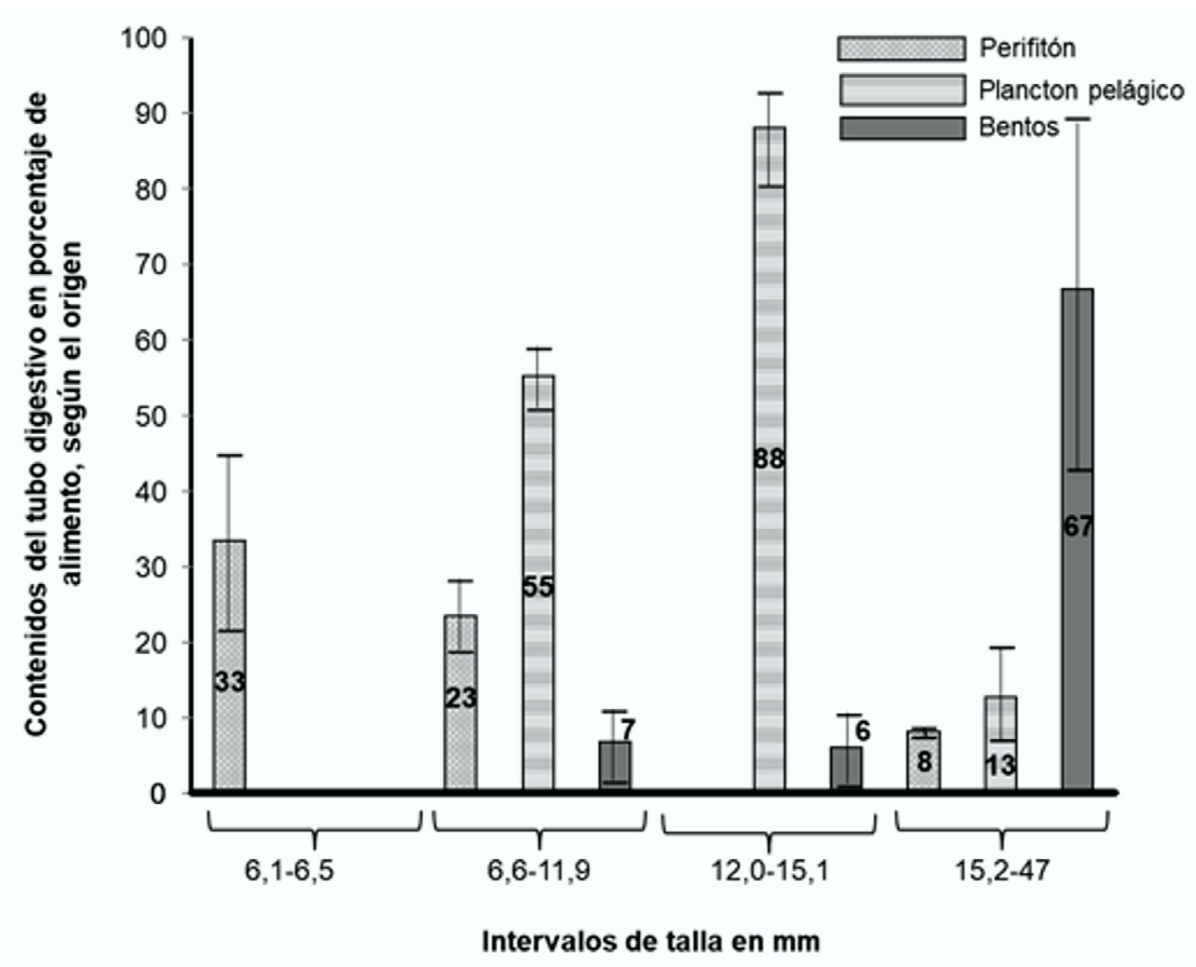

Figura 1. Aporte de contenidos estomacales según los intervalos de talla de las poslarvas de P. mariae

nichos tróficos, como es el caso de $P$. mariae, es importante resaltar que las poslarvas en estas tallas mostraron una tendencia por el plancton pelágico, como se puede observar en la Figura 1.

Las poslarvas con intervalo de 18-20.99; 21-23.99; 2426.99; 27-29.99 mm de LT (Tabla 4), presentan una tendencia a consumir algas Zignemophyceae (44.9\%), como alimento secundario ofertadas por el bentos, siendo los géneros Closterium (55\%), Cosmarium (44 $\%)$, Staurastrum (0.5\%), Spirogyra (0.2\%) y Bambusina $(0.1 \%)$ los más consumidos, debido a lo expuesto anteriormente. Los individuos de estos intervalos de LT, inician un cambio por la oferta alimenticia mostrando una tendencia por el consumo de las comunidades del bentos.

Las poslarvas con intervalo de $30-32.99 ; 33-35.99 ; 36-$ 38.99 y $39-41.99 \mathrm{~mm}$ de LT (Tabla 5 y 6), mostraron preferencia por el consumo de bentos, notándose a su vez, incremento en la ingesta de Zignemophyceae y Bacillariophyceae con los géneros Pinnularia (43.2\%), Navícula $(20.7 \%)$, Frustulia $(32.8 \%$ ) y Tabellaria $(3.2 \%)$. En la Tabla 7, los individuos con tallas entre 42-44.99 y 45-47.99 mm de LT, con 30 días de edad (alevinos) mostraron características morfológicas y anatómicas igual que los adultos, con un nivel trófico detritívoro, observándose en sus CE una preferencia por bacterias, hongos y materia orgánica particulada. Estos resultados coinciden con lo reportado por Sánchez et al., (2013), quienes afirman que los microorganismos, principalmente bacterias, son el alimento de apoyo para detritívoros de partículas finas, siendo una alta calidad de recurso alimenticio.

En el presente estudio se pudo determinar que existe una preferencia alimentaria por $P$. mariae, al cultivarlo en estanques en tierra, donde se definen tres cambios en los niveles tróficos, iniciando con una tendencia por el consumo de perifiton (Clorofíceas y Protozoos), una segunda fase con preferencia por microcrustáceos (cladóceros y copépodos) y por último individuos detritívoros con preferencia por el consumo de materia orgánica particulada (bacterias y hongos).

\section{Agradecimientos}

Los autores agradecen a la Universidad de los Llanos, al Instituto de Investigaciones de la Orinoquia Colombiana IIOC por su apoyo financiero al proyecto de la CONVOCATORIA 01-DB-01-13 y al Instituto de Acuicultura de la Universidad de los Llanos. 


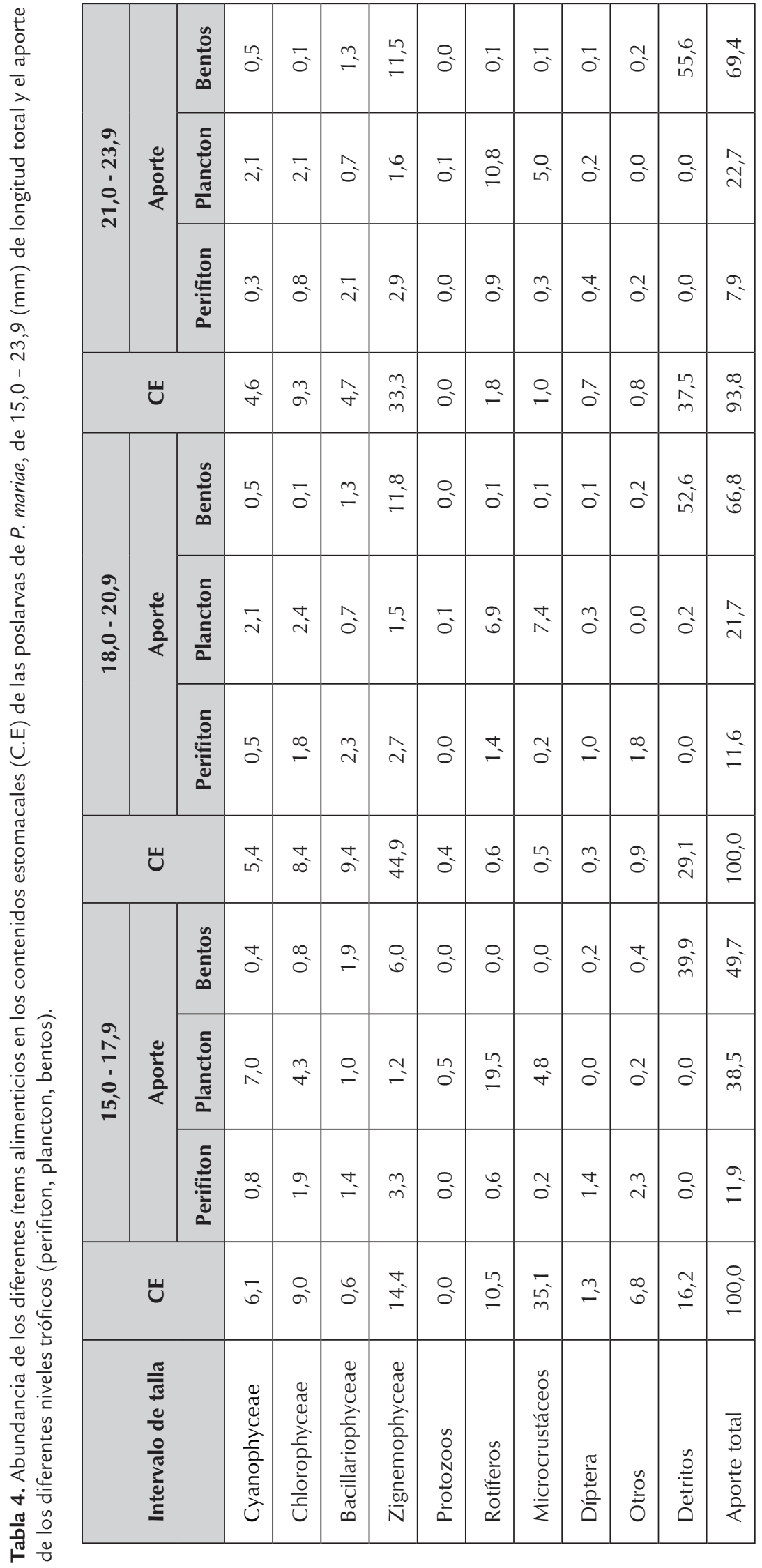




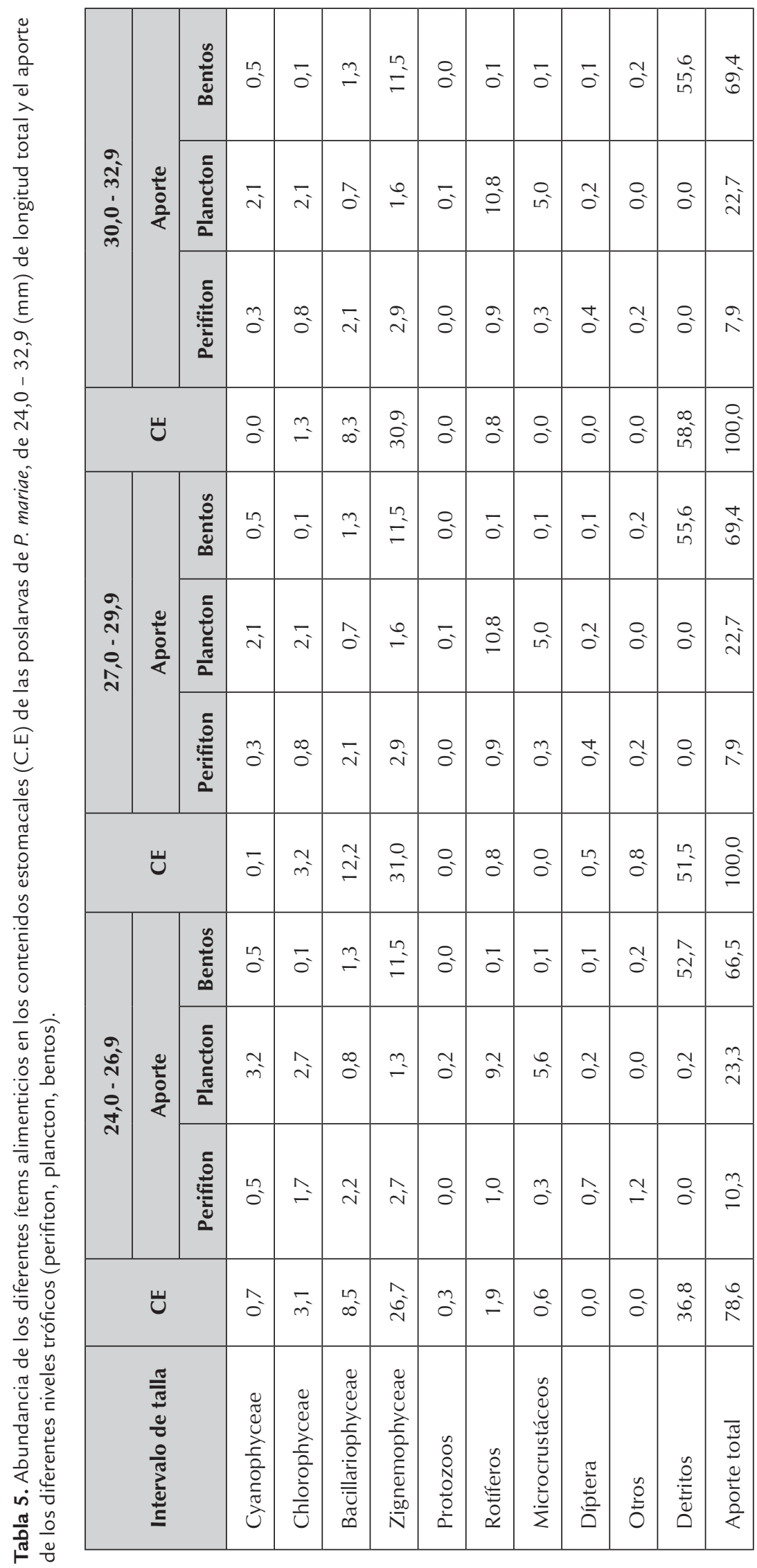




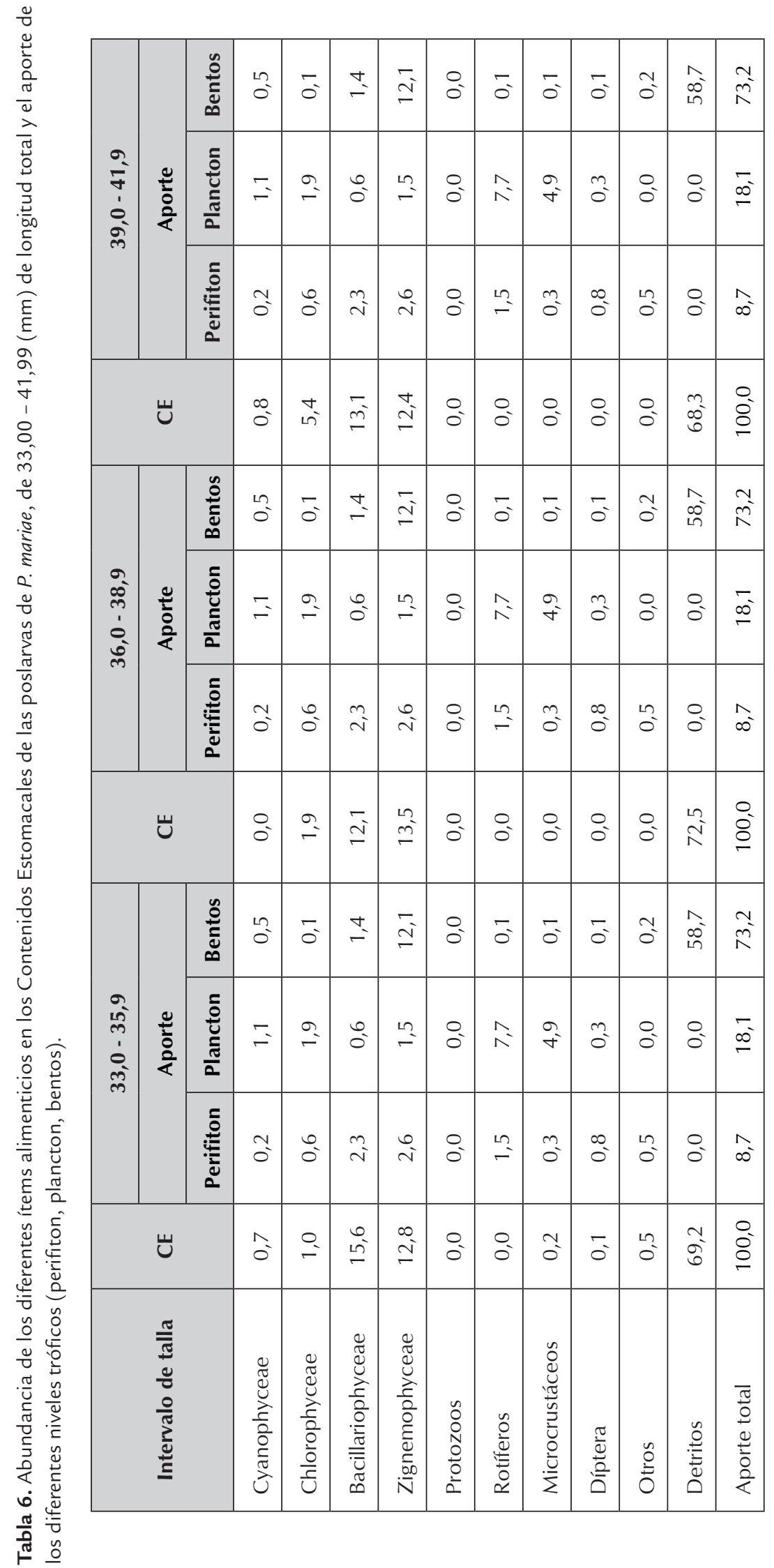


Tabla 7. Abundancia de los diferentes ítems alimenticios en los Contenidos Estomacales de las poslarvas de P. mariae, de 42,00 $47,99(\mathrm{~mm})$ de longitud total y el aporte de los diferentes niveles tróficos (perifiton, plancton, bentos).

\begin{tabular}{|c|c|c|c|c|c|c|c|c|}
\hline \multirow{3}{*}{ Intervalo de talla } & \multicolumn{4}{|c|}{$42,0-44,9$} & \multicolumn{4}{|c|}{$45,0-47,9$} \\
\hline & \multirow{2}{*}{ CE } & \multicolumn{3}{|c|}{ Aporte } & \multirow{2}{*}{ CE } & \multicolumn{3}{|c|}{ Aporte } \\
\hline & & Perifiton & Plancton & Bentos & & Perifiton & Plancton & Bentos \\
\hline Cyanophyceae & 0,0 & 0,0 & 1,9 & 0,6 & 0,0 & 0,0 & 1,9 & 0,6 \\
\hline Chlorophyceae & 1,0 & 0,0 & 2,8 & 0,1 & 0,0 & 0,0 & 2,8 & 0,1 \\
\hline Bacillariophyceae & 10,1 & 1,9 & 0,4 & 1,5 & 18,1 & 1,9 & 0,4 & 1,5 \\
\hline Zignemophyceae & 8,8 & 2,6 & 0,3 & 13,9 & 11,6 & 2,6 & 0,3 & 13,9 \\
\hline Protozoos & 0,0 & 0,0 & 0,0 & 0,0 & 23,5 & 0,0 & 0,0 & 0,0 \\
\hline Rotíferos & 0,0 & 2,9 & 0,3 & 0,1 & 0,0 & 2,9 & 0,3 & 0,1 \\
\hline Microcrustáceos & 0,0 & 0,0 & 0,5 & 0,1 & 0,2 & 0,0 & 0,5 & 0,1 \\
\hline Díptera & 0,0 & 1,1 & 0,4 & 0,1 & 0,0 & 1,1 & 0,4 & 0,1 \\
\hline Otros & 0,0 & 1,1 & 0,0 & 0,3 & 0,0 & 1,1 & 0,0 & 0,3 \\
\hline Detritos & 80,0 & 0,0 & 0,0 & 67,1 & 46,7 & 0,0 & 0,0 & 67,1 \\
\hline Aporte total & 100,0 & 9,7 & 6,5 & 83,7 & 100,0 & 9,7 & 6,5 & 83,7 \\
\hline
\end{tabular}

\section{Referencias}

Atencio-García V, Kerguelén-Durango E, Wadnipar L, Narváez A. Manejo de la primera alimentación del bocachico (Prochilodus magdalenae), MVZ-Córdoba. 2003;8(1):254-260.

Arias CJA. 1995. Contribución al conocimiento biológico de los peces de los Llanos, yamú (Brycon siebenthalae) y sapuara (Semaprochilodus laticeps), con fines de cultivo. Informe. Final. Unillanos-Colciencias. Villavicencio. 65.

Arias-Gallo M, Jiménez-Segura LF, Dorado M. Desarrollo larval de Prochilodus magdalenae (Steindachner, 1879) (Pisces: Prochilodontidae), río Magdalena, Colombia. Revista Actualidades Biológicas. 2010;32(93):199-208.

Beltrán HD, Ajiaco-Martínez RE, Ramírez-Gil H. 2001. Prochilodus mariae. La pesca en la baja Orinoquia: Una visión integral. Instituto Nacional de Pesca y Acuicultura, INPA. Bogotá. 96-99.

Bustamante LF, Quintero LG, Martínez N. Desarrollo larval del coporo Prochilodus mariae, en estanques abonados y con suplemento alimenticio. Dahlia. Revista de la Asociación Colombiana de Ictiólogos. 1997;2:65-69.

CCI Corporación Colombia Internacional, MADR. 2010. Pesca y acuicultura Colombia. Bogotá.
Donato JCH. Análisis limnológico concentración de biocidas en peces de los ríos Ariari, Guayuriba, Humea, Meta. Revista Facultad de Ciencias, Universidad Javeriana. 1987;1(1).

Donoso-Sarmiento J, Guio-Duque JA, Blanco-Racedo J. 1997. Tamaño de la partícula ingerida y relación con la longitud total de poslarvas de bocachico, Prochilodus magdalenae (Steindachner, 1878) (Pisces Characiformes: Prochilodontidae) cultivadas en estanques de la estación piscícola de Repelón. Boletín Científico INPA, 5: 53-73. Bogotá. D.C. Colombia.

Gaviño G, Juárez JC, Figueroa HH. 1982. Técnicas biológicas selectas de laboratorio y de campo. Limusa, México D.F. México.

Heinz S, Dieter K. 1987. Atlas de microorganismos de agua dulce. Ediciones Omega, S.A. 17-190. Barcelona, España.

Hyslop EJ. Stomach contents analysis-a review of methods and their application. Journal. Fish Biology. 1980;17(41):1-429.

López N, Ruiz C, Landines M. Descripción macroscópica del desarrollo larval del coporo (Prochilodus mariae). Revista de Medicina Veterinaria y Zootecnia. 2005;52:110-119.

Mar-Silva V, Hernández MR, Medina NM. Métodos clásicos para el análisis del contenido estomacal en peces. Biológicas. 2014;16(2):13-16.

Paggi JC. Importancia de la fauna de "Cladóceros" (Crustácea, Brachiopoda) del Litoral Fluvial Argentino. Insugeo Miscelánea. 2005;12:239-246. 
Roldán G. 1988. Guía para el estudio de macroinvertebrados acuáticos del departamento de Antioquia. Editorial Presencia Ltda, 217.

Rossi LM. Evolución morfológica del aparato digestivo de poslarvas y pre juveniles de Prochilodus lineatus (Val., 1847) (Pisces, Curimatidae) y su relación con la dieta. Revista Hidrobiológica Tropical. 1992;25(2):159-167.
Sánchez RM, Galvis G, Victoriano PF. Relación entre características del tracto digestivo y los hábitos alimentarios de peces del río Yucao, sistema del río Meta (Colombia). Guyana. 2003;67(1):75-86.

Sánchez R, Ochoa A, Mendoza A. Dieta, selectividad y solapamiento trófico entre las tallas del pez blanco Menidia humboldtiana (Atheriniformes: Atherinopsidae) en el embalse Tiacaque, México. Revista de Biología Tropical. 2013;61(2):787-796. 